\title{
How Sticky Is Sticky Enough? A Distributional and Impulse Response Analysis of New Keynesian DSGE Models
}

\author{
Oleg Korenok ${ }^{1}$ and Norman R. Swanson ${ }^{2}$ \\ ${ }^{1}$ Virginia Commonwealth University and ${ }^{2}$ Rutgers University
}

January 2005

this revision: August 2006

\begin{abstract}
In this paper, we add to the literature on the assessment of how well data simulated from new-Keynesian dynamic stochastic general equilibrium (DSGE) models reproduce the dynamic features of historical data. In particular, we evaluate sticky price, sticky price with dynamic indexation, and sticky information models using impulse response and correlation measures and via implementation of a distribution based approach for comparing (possibly) misspecified DSGE models using simulated and historical inflation and output gap data. One of our main findings is that for a standard level of stickiness (i.e. annual price or information adjustment), the sticky price model with indexation dominates other models. We also find that when a lower level of information and price stickiness is used (i.e. bi-annual adjustment), there is much less to choose between the models (see Bils and Klenow (2004) for evidence in favor of lower levels of stickiness). This finding is due to the fact that simulated and historical densities are "much" closer under bi-annual adjustment.
\end{abstract}

JEL classification: E12, E3, C32

Keywords: sticky price, sticky information, empirical distribution, model selection.

* Oleg Korenok (okorenok@vcu.edu): Department of Economics, VCU School of Business, 1015 Floyd Avenue, Richmond, VA 23284. Norman R. Swanson (nswanson@econ.rutgers.edu): Department of Economics, Rutgers University, 75 Hamilton Street, New Brunswick, NJ 08901, USA. The authors thank the editor and an anonymous referee for numerous insightful and useful comments made on an earlier version of this paper. The authors also thank Laurence Ball, Michael Bordo, Christopher Carroll, Roberto Chang, Valentina Corradi, Bruce Mizrach, Thomas Lubik, Ricardo Reis and seminar participants at Johns Hopkins University and Rutgers University for useful suggestions and comments on earlier drafts of the paper. Swanson has benefited from the support of Rutgers University in the form of a Research Council grant. 


\section{Introduction}

This paper empirically assesses how well data simulated from new Keynesian dynamic stochastic general equilibrium (DSGE) models reproduce various dynamic features of historical data. ${ }^{1}$ The models that we consider include the standard sticky price model discussed in Calvo (1983), the sticky price with dynamic indexation model discussed in Christiano, Eichenbaum and Evans (2001), Smets and Wouters (2003), and Del Negro and Schorfheide (2005), and the sticky information model of Mankiw and Reis (2002). We carry out our evaluation via examination of impulse responses and correlations as well as via use of a distribution based approach for comparing (possibly) misspecified DSGE models using simulated and historical inflation and output gap data. In summary, our analysis can be thought of as an empirical model selection exercise.

One impetus for our study comes from the observation that new Keynesian Phillips curves derived under standard sticky price assumptions have several shortcomings. For example, Ball (1994) has found that such models yield the controversial result that an announced credible disinflation causes booms rather than recessions. Additionally, Fuhrer and Moore (1995) show that the New Keynesian Phillips curve falls short when used to explain inflation persistence, one of the stylized empirical facts describing US inflation. Furthermore, Mankiw and Reis (2002) note that such models have trouble explaining why shocks to monetary policy have delayed and gradual effects on inflation. ${ }^{2}$ Some of the problems of the standard sticky price model are addressed in a series of important papers, including those of Christiano et al. (2001), Smets and Wouters (2003), and Del Negro and Schorfheide (2005) - sticky prices with dynamic indexation, and Mankiw and Reis (2002) - sticky information. ${ }^{3}$ Another impetus for our study comes from the notion that when attempting to reconcile historical and simulation based empirical evidence, we view it as crucial to account for the fact that all models may well be approximations, and so are misspecified. Sources of misspecification include linear approximation solution methods, calibration uncertainty, and the

\footnotetext{
${ }^{1}$ For an overview of recent advances in assessing DSGE models, the reader is referred to Bierens (2005), Bierens and Swanson (2000), Chang, Gomes and Schorfheide (2002), Cogley and Nason (1993), Cogley and Nason (1995a), Diebold, Ohanian and Berkowitz (1998), Fernandez-Villaverde and Rubio-Ramirez (2004), Korenok and Swanson (2006a), Rotemberg and Woodford (1996), Schmitt-Grohe (2000), Watson (1993), and the references cited therein.

${ }^{2}$ Bernanke and Gertler (1995) and Christiano, Eichenbaum and Evans (2000) present empirical evidence supporting this problem noted by Mankiw and Reis (2002).

${ }^{3}$ Sticky information model is representative of the wider class of Rational Inattention (RI) models developed by Phelps (1970), Lucas (1973), and more recently by Mankiw and Reis (2002), Sims (2003), and Woodford (2003b).
} 
fact that the DSGE model is an abstraction of the "truth". For this reason, one of the tools that we use in our empirical analysis is the distributional accuracy assessment methodology of Corradi and Swanson (2005a,b). Some important precedents to our approach to accuracy assessment include DeJong, Ingram, and Whiteman (1996), Geweke (1999a,b), Smith (1993) and Gourieroux, Monfort and Renault (1993). ${ }^{4}$

As might be expected, the three models that we consider have very different properties. For example, Ball, Mankiw and Reis (2003) show that implications with regard to optimal monetary policy are quite different for sticky price and sticky information models. In the sticky price model, inflation enters the loss function, which leads to inflation targeting. It is thus optimal to allow inflation drift in this model. On the other hand, in the sticky information model, inflation drift or inflation targeting is a suboptimal policy, as it is optimal to target the price level. Our approach allows us to shed light on the issue of whether theoretical advantages translate into a better empirical fit, and if not, then why not? To compare of alternative models we follow the suggestion of Mankiw and Reis (2002) and adopt "more realistic" aggregated demand specification. In particular, we extend their sticky information model by specifying standard consumer preferences and money demand. ${ }^{5}$ Thus, aggregate demand is derived from intertemporal household maximization, rather than from a static quantity-theory type of model. This is especially important since we are interested in assessing the empirical performance of alternative models along inflation and the output gap dimensions.

Our findings can be summarized as follows. First, we show in theoretical experiments that the Ball (1994) critique of the sticky price model is limited, in at least one sense. In particular, we show that output booms that proceed disinflation do not occur in experiments with unanticipated disinflation or in the case if the interest rate semi-elasticity is very high. Second, for a standard level of stickiness (i.e. annual price or information adjustment), we find that the sticky price model with indexation dominates other alternatives. The joint distribution of inflation and the output gap simulated from a sticky price model with indexation is "closest" to the historical distribution. Third, we find evidence for a lower level of stickiness than has sometimes been assumed in the literature.

\footnotetext{
${ }^{4}$ DeJong, Ingram and Whiteman (1996), and Geweke (1999a,b) allow for calibration uncertainty with respect to model specification, parameter values, and the actual data's support of the moments of interest. Smith (1993) and Gourieroux, Monfort and Renault (1993) fully account for the fact that DSGE models are misspecified.

${ }^{5}$ Our approach to incorporating consumer preferences and money demand is similar to the approach used by Gali (2002) and Woodford (2003a).
} 
In particular, we note that simulated inflation and output gap data from all of the models that we examine are much "closer" to historical levels when price and information adjustment occurs twice annually than when adjustment occurs annually. Fourth, when the alternative models are calibrated using the lower level of stickiness, there is much less to choose from between the sticky price, sticky price with indexation, and sticky information models. This is because the lower level of stickiness reduces the delays in the response of inflation to monetary policy shocks, so that the sluggish inflation responses generated by the sticky price model with indexation and the sticky information model are no longer strong enough to yield more historically accurate simulated data than that generated by the standard sticky price model (for further discussion of this issue, the reader is referred to Korenok and Swanson (2006b)).

The rest of the paper is organized as follows. Section 2 outlines our DSGE models; Section 3 describe the data used; Section 4 discusses calibration issues, and evaluates theoretical impulse response functions; Section 5 briefly outlines our distributional accuracy testingframework; Section 6 contains the empirical results of our informal and formal comparisons of the models; and Section 7 contains concluding remarks.

\section{New Keynesian DSGE Models for Inflation and the Output Gap}

In this section we outline the sticky price, sticky information and sticky price with indexation models that will be compared and contrasted via impulse response, correlation, and, most importantly, distributional comparison.

Our presentation of the models follows closely along the lines of Gali (2002) and Woodford (2003a). ${ }^{6}$ In the model representative consumer's preferences are represented by standard utility function, labor market is factor specific and consumption is aggregated using a constant elasticity of substitution index. There is a continuum of firms, each producing a differentiated good with a log productivity:

$$
\triangle a_{t}=\rho_{a} \triangle a_{t-1}+\varepsilon_{a, t},
$$

exogenous, difference-stationary stochastic process.

Combining the real marginal cost together with a market clearing condition and the static first order condition from the consumer optimization problem and taking a log transformation yields the

\footnotetext{
${ }^{6}$ For a more detailed exposition, the reader is referred to working paper version Korenok and Swanson (2006b).
} 
equilibrium real marginal cost of the individual firm in terms of output produced by the individual firm, aggregate output and productivity:

$$
m c_{t}(i)=\sigma y_{t}+\omega y_{t}(i)-(1+\omega) a_{t}-\ln (\alpha)
$$

where $m c_{t}(i)$ is a $\log$ of real marginal cost of supplying good $i, y_{t}(i)$ is output of firm $i, y_{t}$ is aggregate output, $\omega=\frac{\psi}{\alpha}+\frac{1}{\alpha}-1, \psi$ is the inverse of the elasticity of labor supply, and $\alpha$ is a production elasticity with respect to labor input. Combining the Euler equation with the market clearing condition results in another equilibrium condition:

$$
y_{t}=-\frac{1}{\sigma}\left(r_{t}-E_{t} \pi_{t+1}-\rho\right)+E_{t} y_{t+1},
$$

where $r_{t}$ is the yield on a nominal riskless one period bond (i.e. the nominal interest rate), $\pi_{t+1}$ is the rate of inflation between $t$ and $t+1, \rho=-\ln \beta$ represents the time discount rate (as well as the steady state real interest rate, given the absence of secular growth), $\beta$ is the subjective discount factor, and $\sigma$ is the inverse of the intertemporal elasticity of substitution.

Following Gali (2002) we postulate (without derivation) a standard money demand equation:

$$
m_{t}-p_{t}=y_{t}-\eta r_{t}
$$

which has unit income elasticity.

\subsection{Optimal Pricing}

In deriving equilibrium behavior it remains to discuss how firms set prices. In this section we describe four alternative models of price setting behavior, the final three of which will be examined in the sequel.

I. Flexible Prices: First, suppose that all firms choose the price of good $i$ each period, independent of prices that were charged in the past, and with full information about current demand and cost. Due to the fact that real marginal costs are increasing in $y_{t}(i)$, the same quantity of each good is supplied, and it is equal to $Y_{t}$. This implies that all firms will choose a common constant markup given by $\mu=\frac{\epsilon}{(\epsilon-1)}$. The flexible price equilibrium process for output is given by:

$$
y_{t}^{n}=\gamma+\psi_{a} a_{t}
$$

where $\psi_{a}=\frac{1+\omega}{\sigma+\omega}$ and $\gamma=\frac{\ln \alpha-\mu}{\sigma+\omega}$. We will refer to the above equilibrium conditions as a natural levels of the corresponding variables. 
II. The Sticky Price Model: Following Calvo (1983), assume that in every period, a fraction, $\left(1-\theta_{1}\right)$, of firms can set a new price, independent of the past history of price changes. This set-up implies that the expected time between price changes is $\frac{1}{1-\theta_{1}}$. Also assume that firms that cannot set their prices optimally have to keep last periods' price (i.e. $P_{t}(i)=P_{t-1}(i)$ ).

III. The Sticky Price Model with Indexation: Modifications of the standard sticky price model have been shown by numerous authors to perform better in empirical applications. For example, we follow Christiano et al. (2001), Smets and Wouters (2003), and Del Negro and Schorfheide (2005), who use dynamic inflation indexation. In this model, as in Calvo (1983), only a proportion of firms, $\left(1-\theta_{2}\right)$, can reset their prices during the current period; but other firms, unable to set prices optimally, set their price equal to: $P_{t}(i)=\Pi_{t} P_{t-1}(i)$.

IV. The Sticky Information Model: Following Mankiw and Reis (2002), assume that all firms reset prices each period. A fraction of firms, $\left(1-\theta_{3}\right)$, use current information in pricing decisions, so that the probability that a firm acts upon the newest information available in a given quarter is $1-\theta_{3}$, independent of the past history of price changes. The remaining fraction of firms use past or outdated information when they set prices.

In these models, the fact that a fraction of firms is not able to adjust prices optimally implies a difference between the actual and the potential (natural) level of output. We denote this difference by $y_{t}^{g}=y_{t}-y_{t}^{n}$, and refer to it as the output gap. Now, solving the associated optimization problems and using a log-linear transformation, we can write expressions for the Phillips curve for each model. ${ }^{7}$ In particular, the dynamics of inflation in the sticky price economy is characterized by New Keynesian Phillips Curve:

$$
\pi_{t}=\beta E_{t} \pi_{t+1}+\lambda_{1} y_{t}^{g}
$$

where $\lambda_{1}=\frac{\left(1-\theta_{1}\right)\left(1-\beta \theta_{1}\right) \xi}{\theta_{1}}$ and $\xi=\frac{\omega+\sigma}{1+\varepsilon \omega}$. In the sticky price model with indexation the above equation has a hybrid New Keynesian Phillips Curve analog:

$$
\pi_{t}=\frac{1}{1+\beta} \pi_{t-1}+\frac{\beta}{1+\beta} E_{t} \pi_{t+1}+\frac{\lambda_{2}}{1+\beta} y_{t}^{g},
$$

where $\lambda_{2}=\frac{\left(1-\theta_{2}\right)\left(1-\beta \theta_{2}\right) \xi}{\theta_{2}}$. Finally, in the sticky information model, dynamics of inflation are

\footnotetext{
${ }^{7}$ For a detailed derivation for the sticky price and the sticky price with indexation models, see Woodford (2003a). For derivation using the sticky information model, see Khan and Zhu (2002).
} 
governed by a sticky information Phillips Curve:

$$
\pi_{t}=\frac{\left(1-\theta_{3}\right) \xi}{\theta_{3}} y_{t}^{g}+\left(1-\theta_{3}\right) \sum_{k=0}^{\infty} E_{t-k-1} \theta_{3}^{k}\left(\pi_{t}+\xi \triangle y_{t}^{g}\right)
$$

Finally, notice that the Euler equation above can be written in terms of the output gap. Namely:

$$
y_{t}^{g}=-\frac{1}{\sigma}\left(r_{t}-E_{t} \pi_{t+1}-r_{t}^{n}\right)+E_{t} y_{t+1}^{g} .
$$

\subsection{Equilibrium Dynamics}

To close our models, we specify a monetary policy rule by assuming that an exogenous path for the growth rate of the money supply is given by the following stationary process:

$$
\triangle m_{t}=\rho_{m} \triangle m_{t-1}+\epsilon_{m, t}
$$

where $\rho_{m} \in[0,1]$.

This yields the desired outcome that: (i) the money demand equation (4), (ii) the equilibrium Euler equation (9), (iii) one of three of the Phillips curve equations: (6), (7) or (8), and (iv) the specification of an exogenous process for technology (1), and (v) an exogenous process for the money supply (10) fully describe the equilibrium dynamics of the economy, and in particular, the dynamics of the (endogenous) output gap and inflation variables in the models.

\section{Data}

Our empirical investigation is based upon the use of quarterly U.S. data for the period 1964:1 and 2003:4. For our measure of inflation, we use the consumer price index (CPI) (the GDP deflator is also used in order to check for the robustness of our results). We construct our measures of the output gap using real GDP. ${ }^{8}$ Our approach to output decomposition is to apply the widely used Hodrick-Prescott (H-P) filter (for a detailed discussion, see Hodrick and Prescott (1997)). ${ }^{9}$

\footnotetext{
${ }^{8}$ We also used the output gap measure constructed by the OECD and the one-sided optimal bandpass filter in order to check the robustness of our results. Empirical results were qualitatively the same as those reported here, and are available upon request.

${ }^{9}$ The H-P filter minimizes the sum of squared deviations of the actual output, $y_{t}$, from the estimated trend, $\tau_{t}$, subject to a smoothness constraint. Formally, it minimizes:

$$
\min _{\tau_{t}} \sum\left(y_{t}-\tau_{t}\right)^{2}+\lambda \sum\left(\left(\tau_{t+1}-\tau_{t}\right)-\left(\tau_{t}-\tau_{t-1}\right)\right)^{2}
$$
}


All data were obtained from the OECD Main Economic Indicators database (Database Edition (ISSN 1608-1234)), where both yearly and quarterly data are available. We report results based on quarterly data, although results based on yearly data were compiled, and yield qualitatively similar conclusions. Of note is that we remove the mean of the historical inflation data in order to make the data directly comparable to analogous inflation data simulated using the DSGE models. The historical output gap data is directly comparable with data simulated from the DSGE models.

\section{Calibration and Theoretical Impulse Response Analysis}

In this section we discuss calibration of the models and present the results of a preliminary theoretical impulse response analysis of the alternative DSGE models.

With regard to calibration, we follow Gali (2002). Namely, assume log utility of consumption, so that $\sigma=1$. Also, set the labor wage elasticity as $\psi=1$, and set the value of the elasticity of money demand with respect to the interest rate as $\eta=1$, which is consistent with the interest rate elasticity found in empirical work and used in other calibration studies (see e.g. Mankiw and Summers (1986), Stock and Watson (1993)). The Dixit-Stiglitz elasticity of substitution is set to $\epsilon=11$, which implies a $10 \%$ markup of price over marginal cost; and the consumer discount factor is set to $\beta=0.99$, which implies an average annual interest rate $4 \%$. We set the labor share parameter to $\alpha=2 / 3$.

The degree of information and price stickiness, $\theta$, was chosen to be common across all models and is initially set to $\theta=0.75 .{ }^{10}$ This implies yearly price or information updating. This choice is common in many theoretical (see e.g. Gali (2002), Gali, Lopez-Salido and Valles (2003), and Woodford (2003a)) and empirical studies (see e.g. Blinder, Canetti, Lebow, and Rudd (1998), Gali and Gertler (1999), Khan and Zhu (2002), Korenok (2004), Sbordone (2002), and Smets and Wouters (2003)). In addition, we subsequently compare models with a lower degree of information and price stickiness, namely $\theta=0.5$. The motivation for this lower level of stickiness comes from Bils and Klenow (2004), who study price stickiness by examining 350 categories of goods and where $\lambda$ is a parameter that is usually set to 1600 for quarterly data. Formally, the output gap, $y_{t}^{g}$, is defined as $y_{t}-\tau_{t}$. Of note is that the H-P filter was also used to compare historical and artificial (model simulated) data by Backus, Kehoe and Kydland (1992), Cooley and Hansen (1989), and Kydland and Prescott (1982), among others.

${ }^{10}$ Our motivation for common value for information and price stickiness comes from the fact that empirical estimates of information and price stickiness are quite close. 
services, constituting about $70 \%$ of consumer spending, and find evidence of more frequent price changes than hitherto suspected.

Finally, the exogenous processes are calibrated in the following way. For the technology growth rate, we set the value of the autoregression coefficient, $\rho_{a}$, equal to zero, and the standard deviation equal to $\sigma_{a}=0.007$. The low value of $\rho_{a}$ accounts for the low autocorrelation of output growth and common measures of the output gap. Of further note is that the usual standard deviation for the technology growth rate is at or below 1\% (see e.g. Gali (2002) or Gali et al. (2003)). The autoregression coefficient of growth in the money supply is set equal to $\rho_{m}=0.5$, and the standard deviation is set equal to $\sigma_{m}=0.007$; a value which is close to the estimated parameters for autoregressive processes describing M0 or M1 growth rates in the United States. ${ }^{11}$

We now turn to a discussion of impulse response functions in the sticky price, sticky price with indexation and sticky information models. In the discussion, we use our "baseline" calibration, where all parameters are as given above, and where $\theta_{i}=0.75$. Conclusions from the "baseline" calibration also apply to our alternative calibration where $\theta_{i}=0.5$, which is motivated and discussed in Section 6.3.

\subsection{Experiment: Response to An Anticipated Disinflation}

We can replicate the theoretical experiment of Mankiw and Reis (2002): namely, an announced and credible shift in the money growth rate. The purpose of their experiment was to illustrate a problem in sticky price models pointed out by Ball (1994), in that an announced credible disinflation causes booms rather than recessions, and their purpose was to show that sticky information models address this problem. We replicate their experiment using the DSGE model specified and calibrated as discussed above.

Inflation responses to announced ( 8 quarters in advance) and credible disinflations in sticky price, sticky information, and sticky price with indexation models are presented in Figure 1. In the sticky price model, inflation moves in anticipation of demand. It falls in the announcement period and then slowly decreases to 0 after 9 years. In the sticky price model with indexation there is no initial fall; inflation decreases smoothly, and reaches 0 after 3.5 years. Furthermore, after the 4th year, it oscillates around 0. In the sticky information model, inflation does not respond

\footnotetext{
${ }^{11}$ See Mankiw and Reis (2002), Cooley and Hansen (1989), and Yun (1996) for further justification of this calibration.
} 
immediately, and the eventual response is very small, although it accelerates, reaching a peak during the implementation period. Such behavior does not necessarily mean that agents do not take into account the announcement. Indeed, we should expect such behavior if agents update their information sets on average every 4 quarters, and if the announcement is made 8 quarters in advance. The timing of updates means that at the date of actual policy implementation, half of the agents have already included the new policy in their information sets.

The response of the output gap to an announced disinflation is presented in the bottom of Figure 1. In the sticky price model, the anticipated disinflation results in an increase in the output gap. This increase can be explained by the money demand equation. The output gap increases because inflation falls between announcement and implementation of the disinflation policy, while money growth remains constant. This leads to an increase in real money balances and to higher output, while the natural output level remains constant. ${ }^{12}$ The output gap also increases in the sticky price model with indexation. However, the increase is much lower than in the sticky price model, and the output gap returns to 0 after 2 years. Thereafter, it remains negative for 4 years. Indeed, the cumulative response in this case is negative. The slower increase, and then decrease, in the output gap is due to the fact that there is an inflation inertia built into the sticky price model with indexation model. The fall in inflation is lower than in the sticky price model, and with constant money growth leads to a lower increase in real money balances and a lower increase in the output gap. In contrast to the sticky price model, the output gap declines in the sticky information model from the beginning. Inflation responds very slowly because most of the agents set prices based on an old information set, in which they did not expect inflation to change. After the announcement takes place, inflation declines more slowly than money growth, because not all agents have had the opportunity to introduce the announcement into their information sets. Thus, real money balances and output fall, while the natural output level remains constant.

In summary, experiment supports Ball's (1994) argument. However, it should be noted that implementation of the experiment is somewhat unusual given that we assume a permanent shock to inflation and a credible announced disinflation.

\footnotetext{
${ }^{12}$ We do not discuss interest rate effects because the size of the interest rate change is small in our experiment relative to the change in output.
} 


\subsection{Robustness of Experiment Results}

Ball (1994) and Mankiw and Reis (2002) conducted an equivalent of the above experiment for permanent shock anticipated 1 period ahead and 8 periods ahead respectively. Both experiments resulted in disinflationary boom, i.e. boom after announced, credible decline of money supply. On the other hand, Mankiw and Reis (2002) show that after transitory unanticipated shock there is no disinflationary boom. Trabandt (2005) in a different setup finds that both anticipated 8 periods ahead and unanticipated shocks result in recession. He concludes that previous outcomes were driven by the fact that both Ball (1994) and Mankiw and Reis (2002) assumed zero semi-elasticity of money demand with respect to interest rate, parameter $\eta$ in equation 4 . Interest rate semielasticity determines the relative size of interest rate decrease compared to increase in real money balances after disinflationary shock, thus it determines change in output in equation 4. Finally, in our experiment we find that permanent anticipated 8 periods ahead negative shock to money supply growth results in boom, even though $\eta$ is equal to one.

Here we show why outcomes in all these experiments are different. In particular, we check robustness of the disinflationary boom to changes in: (i) persistence of the shock $\left(\rho_{m}\right)$, (ii) anticipation period $(\mathrm{k})$ and (iii) semi-elasticity of money demand with respect to interest rate $(\eta)$. All other parameters are at their baseline calibrated values (since values of other parameters influence the value of the output we focus on ordinal relationships). For each experiment design and parameters choice we report maximum of the output gap response to negative money supply shock. We take positive maximum as indication of disinflationary boom.

Figure 2 reports robustness of disinflationary boom to changes in $\eta, k$ and $\rho_{m}$. We report results only for sticky price model. ${ }^{13}$ There is little dependence of disinflationary boom on persistence of money supply shock, Graph A. The maximum value of the output gap somewhat increases as persistence of the process increases from very persistent to permanent. For $\eta=0$ and any anticipation period, $k$ from 1 to 8 on Graph $\mathrm{B}$, disinflationary boom exists which is in line with Ball (1994) and Mankiw and Reis (2002) results. While for $k=0$ there is no disinflationary boom which is in line with Mankiw and Reis (2002) and Trabandt (2005) experiments with unanticipated shocks. For high values of $\eta$, Graphs A and B, disinflationary boom occurs independent of anticipation

\footnotetext{
${ }^{13}$ Results for sticky price model with indexation are very close to the sticky price model results, while results for sticky information model are trivial, i.e. there are no disinflationary booms for any experiment design or reparametrization.
} 
period or persistence of the shock which is in line with Trabandt (2005) findings. For his choice of utility function and baseline calibration $\eta=50$ and interest rate effect dominates change in demand for real money balances. On the other hand, most of the empirical estimates of semi-elasticity are below or close to 1 as we pointed out in our calibration section. ${ }^{14}$

Our robustness exercise demonstrates that disinflationary boom is not robust to design of experiment or parameters choice, i.e. if shocks are unanticipated or if semi-elasticity of money demand with respect to interest rate is very high, negative shock to money demand growth is followed by recession. Since most of empirical research concentrated on unanticipated shocks and we are using empirical findings to motivate our calibrations, we consider only this kind of shocks in the paper (our calibration is in the low-right corner of Graph B). In this we follow Mankiw and Reis (2002), who comment that they "take a step toward greater realism" when they analyze transitory monetary shocks.

\subsection{Response to a Contractionary Monetary Policy Shock}

The left column of Figure 3 reports impulse response functions for inflation (top graph) and the output gap (bottom graph), given that a contractionary monetary policy shock is imposed in our baseline calibration of the three DSGE models (recall that the baseline model sets $\theta=0.75$ ). Notice that inflation responds immediately in the sticky price model, with the highest response in the initial period. Furthermore, notice that the lack of lags in the response to the monetary policy shock for a model with sticky prices was also pointed out by Mankiw and Reis (2002). The dynamics of inflation after the initial shock is very persistent for all three models, in contradiction to the point made by Fuhrer and Moore (1995) that inflation is not persistent in sticky price models. Furthermore, the response of inflation in the sticky price model with indexation and the sticky information model displays inflation inertia. The maximum impact of the monetary policy shock on inflation occurs after 5 quarters for the sticky price model with indexation and after 7 quarters for the sticky information model. Finally, note that the inflation response is the highest for the sticky price model with indexation, while for the sticky price model and the sticky information model, the size of the response is comparable.

In all three models the output gap response to a transitory, unanticipated shock is similar.

\footnotetext{
${ }^{14}$ With exception of Ireland (2004) estimate of semi-elasticity in general equilibrium framework, which is 7.75 with standard error 1.75 .
} 
Namely, the response is negative and hump-shaped, and there is a fast initial response. The response decreases over the first two quarters and then increases. On further note is that the size of the responses for the different models is very close, while the speed of recovery is much faster for the sticky price model with indexation than for the other models.

To summarize, in a more standard setups it appears that disinflation dynamics are much closer amongst the competing models. In all cases, both inflation and the output gap decrease. However, the sticky price model with indexation and the sticky information models have more inflation inertia than the sticky price model. It is worth noting, however, that the decline in inflation in our calibrated models may also be occurring in the current context because of contractionary technology shocks. Thus, we next consider an experiment where there is a contractionary technology shock.

\subsection{Response to a Contractionary Technology Shock}

The left column of Figure 4 reports the impulse response functions for inflation (top graph) and output (bottom graph), given that a contractionary technology shock is imposed in our baseline calibration of the three DSGE models.

As in the case of the monetary policy shock, a technology shock leads to an immediate inflation response, with the highest response in the initial period. The response of inflation in the sticky price model with indexation and the sticky information models, however, displays inflation inertia. Furthermore, the size of the response is somewhat lower than the size of response to monetary policy shock.

The output gap response to a technology shock is similar for all three models. Namely, the response is negative, with a fast initial response. Unlike the output gap response to a monetary policy shock, the responses to a technology shock are not hump shaped and the size of response is lower for all models. On further note is that the size of the responses for the models is very close, while the speed of recovery is much faster for the sticky price model with indexation than for the other models.

To summarize, the response to a technology shock is somewhat smaller in size and the output gap response is not hump shaped. Otherwise, the dynamics of the response of inflation and the output gap after a contractionary shock to technology is very close to the dynamics of the response after contractionary monetary shock. 


\section{A Distribution Comparison Test for DSGE Models}

In this section we briefly discuss the distributional accuracy test discussed in Corradi and Swanson (CS: 2005b), which shall be used in our subsequent empirical analysis. Of note is that the following approach to DSGE model evaluation is but one of many approaches currently in use by economists (see discussion in the introduction for further remarks in this regard). ${ }^{15}$

Assume that our objective is to compare the joint distribution of the historical data with the joint distribution of the simulated series. Following CS, and for the sake of simplicity (but without loss of generality), we limit our attention in the section to the evaluation of the joint empirical distribution of (actual and model-based) current and previous period output. In principle, if we have a model driven by $k$ shocks, then we can consider the joint CDF of $k$ variables plus an arbitrary (but finite) number of lags of each variable.

Consider $m$ DSGE models, and set model 1 as the benchmark model. We require at least one of the competing models (e.g. model $j$ for $j=2, \ldots, m$ ) to be nonnested with respect to the benchmark, a requirement which is satisfied in the current context when model parameters such as $\theta_{i}, i=1,2,3$ are calibrated and are not estimated (when freely estimated all parameters could be identically zero, leading to nestedness). For the sake of notational ease of expression, let $\Delta \log X_{t}, t=1, \ldots, T$ denote the actual historical (output) series, and let $\Delta \log X_{j, n}, j=1, \ldots, m$ and $n=1, \ldots, S$, denote the output series simulated under model $j$, where $S$ denotes the length of the simulated sample. In general, some parameters in the DSGE models may be kept fixed (at their calibrated values), while others may be estimated.

Along these lines, denote $\Delta \log X_{j, n}\left(\widehat{\Theta}_{j, T}\right), n=1, \ldots, S, j=1, \ldots, m$ to be a sample of length $S$ drawn (simulated) from model $j$ and evaluated at the parameters estimated (or calibrated) under model $j$, using the $T$ available historical observations. ${ }^{16}$ We assume stationarity in our subsequent

\footnotetext{
${ }^{15}$ The test discussed in this section is not meant to be informative about the source of the rejection. In this sense, our distributional comparisons are weak tests of DSGE theories. Alternative approaches to that taken here include the study of ARMA models, wherein restrictions implied by the different theories can be imposed, and the construction of tests of cross-equation restrictions. Much of this is done in the papers cited at the beginning of the introduction, and key papers along these lines include Cogley and Nason (1995a) and Geweke (1999b). Adaptation of the distributional approach taken here to the examination of the auto- and cross-correlation functions discussed earlier, for example, are left to future research.

${ }^{16}$ In practical applications, $\widehat{\Theta}_{j, T}$ is usually a combination of estimated and calibrated parameters. However, in our empirical analysis, all parameters are calibrated, and hence there is no parameter estimation error.
} 
analysis. ${ }^{17}$ On the other hand, endogenous business cycles models that predict persistent, but stationary, fluctuations should not be treated in this manner in order to avoid potential problems associated with overdifferencing. In general, we require both the actual and the simulated series to be (strictly) stationary and mixing.

For ease of exposition, and in keeping with our focus on current and lagged values of the variable of interest, let $Y_{t}=\left(\log \Delta X_{t}, \log \Delta X_{t-1}\right), Y_{j, n}\left(\widehat{\Theta}_{j, T}\right)=\left(\Delta \log X_{j, n}\left(\widehat{\Theta}_{j, T}\right), \Delta \log X_{j, n-1}\left(\widehat{\Theta}_{j, T}\right)\right)$. Also, let $F_{0}\left(u ; \Theta_{0}\right)$ denote the distribution of $Y_{t}$ evaluated at $u$ and $F_{j}\left(u ; \Theta_{j}^{\dagger}\right)$ denote the distribution of $Y_{j, n}\left(\Theta_{j}^{\dagger}\right)$, where $\Theta_{j}^{\dagger}$ is the probability limit of $\widehat{\Theta}_{j, T}$, taken as $T \rightarrow \infty$, when parameters are estimated, and where $u \in U \subset \Re^{2}$, possibly unbounded. Accuracy is measured in terms of square error. The squared (approximation) error associated with model $i, i=1, \ldots, m$, is measured in terms of the (weighted) average over $U$ of $E\left(\left(F_{i}\left(u ; \Theta_{i}^{\dagger}\right)-F_{0}\left(u ; \Theta_{0}\right)\right)^{2}\right)$, where $u \in U$, and $U$ is a possibly unbounded set on $\Re^{2}$. The rule is to choose Model 1 over Model 2 if

$$
\int_{U} E\left(\left(F_{1}\left(u ; \Theta_{1}^{\dagger}\right)-F_{0}\left(u ; \Theta_{0}\right)\right)^{2}\right) \phi(u) d u<\int_{U} E\left(\left(F_{2}\left(u ; \Theta_{2}^{\dagger}\right)-F_{0}\left(u ; \Theta_{0}\right)\right)^{2}\right) \phi(u) d u
$$

where $\int_{U} \phi(u) d u=1$ and $\phi(u) \geq 0$ for all $u \in U \subset \Re^{2}$. For any evaluation point, this measure defines a norm and it implies a usual goodness of fit measure. The hypotheses of interest are:

$$
H_{0}: \max _{j=2, \ldots, m} \int_{U} E\left(\left(F_{0}\left(u ; \Theta_{0}\right)-F_{1}\left(u ; \Theta_{1}^{\dagger}\right)\right)^{2}-\left(F_{0}(u)-F_{j}\left(u ; \Theta_{j}^{\dagger}\right)\right)^{2}\right) \phi(u) d u \leq 0
$$

versus

$$
H_{A}: \max _{j=2, \ldots, m} \int_{U} E\left(\left(F_{0}\left(u ; \Theta_{0}\right)-F_{1}\left(u ; \Theta_{1}^{\dagger}\right)\right)^{2}-\left(F_{0}(u)-F_{j}\left(u ; \Theta_{j}^{\dagger}\right)\right)^{2}\right) \phi(u) d u>0 .
$$

Thus, under $H_{0}$, no model can provide a better approximation (in square error sense) to the distribution of $Y_{t}$ than the approximation provided by model 1 . In order to test $H_{0}$ versus $H_{A}$, the relevant test statistic is $\sqrt{T} Z_{T, S}$, where:

$$
Z_{T, S}=\max _{j=2, \ldots, m} \int_{U} Z_{j, T, S}(u) \phi(u) d u,
$$

\footnotetext{
${ }^{17}$ In our analysis, we use the H-P filter to induce stationarity on the output gap measure, while inflation is assumed stationary. Thus, the output gap data that we examine is potentially problematic, as the filter ignores cointegration, for example. However, it should be noted that there is mixed empirical evidence of the usefulness of imposing cointegration restrictions when forecasting. Furthermore, we carried out our analysis replacing our output gap with alternative measures of the output gap, and results were qualitatively the same. Finally, it should be stressed that an excellent frequency domain based approach to the problem of constructing goodness of fit tests that are invariant to linear filtering is explored in Cogley and Nason (1995b).
} 
and

$$
\begin{aligned}
Z_{j, T, S}(u)= & \frac{1}{T} \sum_{t=1}^{T}\left(1\left\{Y_{t} \leq u\right\}-\frac{1}{S} \sum_{n=1}^{S} 1\left\{Y_{1, n}\left(\widehat{\Theta}_{1, T}\right) \leq u\right\}\right)^{2} \\
& -\frac{1}{T} \sum_{t=1}^{T}\left(1\left\{Y_{t} \leq u\right\}-\frac{1}{S} \sum_{n=1}^{S} 1\left\{Y_{j, n}\left(\widehat{\Theta}_{j, T}\right) \leq u\right\}\right)^{2} .
\end{aligned}
$$

From equation (11), it is immediate to see that the computational burden increases with the dimensionality of $U$, that is with the number of variables and/or lagged values we are considering. ${ }^{18}$ Bootstrap critical values for the above test can be obtained in a straightforward manner, as outlined in CS. ${ }^{19}$ Additionally, valid bootstrap critical values in the context of recursive estimation is discussed in Corradi and Swanson (2006).

\section{Empirical Comparison of Simulated and Historical Data}

This section presents results from an empirical comparisons of simulated and historical inflation and output gap data.

\subsection{Basic Data Analysis $(\theta=0.75$ - High Degree of Price Stickiness)}

In order to form an initial impression of the performance of our alternative models, we first plot empirical density functions for simulated and historical inflation and output gap observations, where all simulation based calculations are based on samples of length 100T ( $\mathrm{T}$ is the historical sample size). In a subsequent section (Section 6.3), we consider the case where $\theta=0.5$ (i.e. twice annual adjustment), at which point we compare all models and calibrations using various other statistical measures, including autocorrelation and cross correlation functions, directional accuracy, and the well known acceleration phenomenon.

Empirical densities of actual and simulated inflation and output gap distributions for $\theta=0.75$ are plotted in the two left hand side panels of Figure 5. Of note is that for inflation, the empirical density of the sticky price model with indexation appears "closest" to the historical density. Clearly,

\footnotetext{
${ }^{18}$ The limiting distribution of $\sqrt{T} Z_{T, S}$ is a zero mean Gaussian process with a covariance kernel that reflects the contribution of parameter estimation error, the time series structure of the data and, for $\delta>0$, the contribution of simulation error.

${ }^{19}$ For further details see appendix of the working paper version Korenok and Swanson (2006b).
} 
though, none of the models perform well at mimicking the left tail of the historical distribution, as is apparent upon inspection of empirical densities beyond the 0.01 on the horizontal axis of the plots. For the output gap, the empirical density of the sticky price model with indexation is still the "closest" to the historical density. However, in this case none of the simulated distributions are particularly accurate, as evidenced by the poor fit at both tails of the historical density. Interestingly, inflation values simulated using all models appear to have distributions with tails that are too thin, while the opposite can be said for the output gap.

\subsection{Distributional Accuracy Tests $(\theta=0.75$ - High Degree of Price Stickiness $)$}

We now turn to a more formal discussion of the results discussed in the previous sub-section. In particular, we apply the distributional accuracy test discussed above. Results are gathered in Table 1. The table is organized as follows. The first column gives $S$, the length of the simulation sample used, and $l$, the block length used in the construction of test critical values. The second column of entries reports the numerical values of the test statistic $\left(Z=Z_{T, S}\right)$ discussed above, while the next four columns report $5 \%$ and $10 \%$ bootstrap critical values based on a bootstrap statistics for the cases where $T / S \rightarrow \delta>0\left(Z^{* *}\right)$ and $T / S \rightarrow 0\left(Z^{*}\right)$, where $T$ denotes the historical sample size. The last three columns report the Corradi and Swanson (2005a) distributional loss measure associated with model $i, i=1,2,3$, (i.e. $\left.\int_{U} \frac{1}{T} \sum_{t=1}^{T}\left(1\left\{Y_{t} \leq u\right\}-\frac{1}{S} \sum_{n=1}^{S} 1\left\{Y_{i, n}\left(\widehat{\theta}_{1, T}\right) \leq u\right\}\right)^{2} \phi(u) d u\right)$ - see Section 5 for further details. As noted previously, $T$ denotes the historical sample size. For the case where $S=T$, we set the block length used in the bootstrap as follows: $l 1=5, l 2=8, l 3=10$, $l 4=16$ and $l 5=20$. For all other cases, where $S=a T$, say, we set $l$ equal to ' $a$ ' times the corresponding value of $l$ when $S=T$. Selected results are reported in the table (results for the other values of $S$ and $l$ are qualitatively the same are tabulated in the working paper version - see Korenok and Swanson (2006b)). All statistics are based on grids of 20x20 values for $u$, distributed uniformly across the historical data ranges of $\pi_{t}$ and $y_{t}^{g}$. Bootstrap empirical distributions are constructed using 500 bootstrap replications.

We begin by setting the sticky price model as the benchmark, against which we compare our two alternative models - the sticky price with indexation model and the sticky information model. Additionally, tests are constructed using three different joint distributions. Namely (i) inflation and lagged inflation, (ii) output gap and lagged output gap, and (iii) inflation and the output gap. In Panel I.C of Table 1, results for case (iii) are given. Of note is that the benchmark sticky 
price model is almost always rejected at conventional $5 \%$ and $10 \%$ levels, regardless of simulation sample size and bootstrap block length. This constitutes strong evidence in favor of the alternative models. Interestingly, upon inspection of Panels I.A and I.B, the same result holds (for virtually all sample size/block length permutations). Thus, for cases (i), (ii), and (iii), the sticky price model appears to be dominated by the alternative models, in accord with our earlier interpretation of the distributional and density plots of simulated and historical data. Furthermore, inspection of the last three columns in the three tables indicates that the CS distributional loss measure is always lowest for the sticky price with indexation model, suggesting that the sticky price with indexation model is the "best" based on our point mean square error type distributional loss measure, and is thus likely to be the model driving the rejections of the test.

In order to shed further light on the issue of whether our test is rejecting because of the dominant performance of the sticky price with indexation model, we also performed several bi-model tests (results are available upon request from the authors). In particular, we tested: (i) the sticky price model against an alternative of the sticky price with indexation model, (ii) the sticky price model against an alternative of the sticky information model, and (iii) the sticky information model against an alternative of the sticky price with indexation model. Interestingly, in all cases the null model is rejected in favor of the alternative model, suggesting an ordering as follows: the sticky price with indexation model, followed by the sticky information model, followed by the sticky price model. As we shall shortly see, however, this result is highly dependent upon the level of price stickiness.

\subsection{Basic Data Analysis $(\theta=0.5$ - Low Degree of Price Stickiness)}

based on our comparison of simulated and historical density functions (see above discussion) for the case where $\theta=0.75$, it wasnoted that the distributions of simulated inflation for all three models have thinner tails than in the historical record. Also, the distributions of the simulated output gap for all three models have thicker tails than in the historical record. It follows that in order to improve the fit of the models, the response of inflation to shocks should be larger, and the response of the output gap should be smaller. Unfortunately, it is not possible to achieve a larger response for inflation and a smaller response for the output gap by choosing different values for the volatility of the shocks in the models. On the other hand, a larger response of inflation and a smaller response of the output gap is expected for a given shock volatility if the level of price stickiness is reduced. For example, a decrease in price stickiness, allows a larger fraction of agents 
in the economy to adjust prices, which in turn produces a larger response of inflation. At the same time, a larger inflation response coupled with a money growth shock that is the same size as prior to the decrease in price stickiness leads to a decrease in the response of real money balances and thus output. These facts, coupled with the results of the study by Bils and Klenow (2004) discussed above, provide the impetus for our second calibration, where we set $\theta=0.5$. Of note is that the decrease from $\theta=0.75$ (i.e. 12 months between price changes) to $\theta=0.5$ (i.e. 6 months between price changes) still results in price stickiness slightly higher than the 4.3 months suggested in Bils and Klenow.

We begin our basic data analysis with a discussion of impulse response functions analogous to those discussed in Section 4. In particular, compare the right hand side panels in Figures 3 and 4 to the left side panels in the same figures. The following conclusions emerge. First, the size of the inflation response to both shocks increases when information and price stickiness is reduced. In fact, for the monetary shock the inflation response is twice as big. Additionally, the size of the output gap response to both shocks decreases with the largest decrease due to monetary policy shock. Finally, the decrease in stickiness also leads to a decrease in the length of response.

Next we discuss the simulated distributions and densities given in the right hand side panels of Figure 5 (i.e. the case where $\theta=0.5$ ). Interestingly, the simulated distributions of inflation for all three models are much closer to the historical record for the lower level of stickiness (i.e. $\theta=0.5$ ). For the higher level of information and price stickiness (i.e. see left column of the figure), the sticky price model with indexation is the closest to historical inflation. On the other hand, for lower levels of stickiness (i.e. see right column of the Figure), there is no clear winner among the three models. In addition all three models fail to reproduce the right tail asymmetry of the historical distribution of inflation. The simulated distributions of the output gap for all three models are much closer to the historical record for the lower level of stickiness. Nevertheless it is again worth noting that all three models continue to fail to capture the small left tail asymmetry of the historical distribution of the output gap. Overall, it is clear that for the low level of stickiness, the simulated distributions for all three models are closer to the historical record. However, when the level of stickiness is low there appears to be little to choose between the models based on inspection of empirical densities and distributions. ${ }^{20}$

\footnotetext{
${ }^{20}$ See working paper version of this paper for further discussion.
} 
Results reported in Table 2 are contingency tables constructed for the higher and lower information and price stickiness levels In particular, contingency tables based on historical and simulated joint distributions of inflation and lagged inflation are given in Panel A, while those for the output gap and lagged output gap are given in Panel B, and those for inflation and the output gap are given in Panel C. Different columns represent different models (the exception is the column which contains results for the historical data), while each row gives percentage of movements in different directions, with the exception that the last row of entries in each panel of the table reports $p$-values for the classical $\chi^{2}$ test for independence based on $2 \mathrm{x} 2$ contingency tables (see Swanson and White (1995) for further discussion). Of note is that for our high level of stickiness, the results in Part I of the table indicate that none of the models are able to mimic historical behavior. For the low level of stickiness (see Part II of the table), performance does not improve suggesting that there is little to choose between either the models or the level of stickiness based on the evaluation of contingency tables.

Table 3 contains auto- and cross-correlations for inflation and the output gap. Entries in the table correspond to autocorrelations of inflation $\left(\operatorname{corr}\left(\pi_{t}, \pi_{t-1}\right)\right)$ and the output gap $\left(\operatorname{corr}\left(y_{t}, y_{t-1}\right)\right)$, as well as the cross correlation between inflation and the output gap. Corresponding historical values are: $\operatorname{corr}\left(\pi_{t}, \pi_{t-1}\right)=0.8363, \operatorname{corr}\left(y_{t}, y_{t-1}\right)=0.8690, \operatorname{corr}\left(y_{t}, \pi_{t}\right)=0.2582$. Values are computed for different simulation samples of length $\mathrm{S}=5 \mathrm{~T}, 10 \mathrm{~T}, 20 \mathrm{~T}, 30 \mathrm{~T}, 50 \mathrm{~T}, 100 \mathrm{~T}$, where $\mathrm{T}$ is the historical data sample size. For our high level of stickiness (i.e. $\theta=0.75$ ), the sticky price model with indexation better reproduces historical cross-correlations between inflation and the output gap, while the sticky price model fares better at reproducing autocorrelation features for inflation and the output gap. For our lower level of stickiness, the sticky price model better reproduces autocorrelation features for the output gap and cross-correlation between inflation and the output gap, while the sticky price model with indexation better reproduces historical autocorrelation of inflation.

Finally, we compare the ability of the models to reproduce the so-called acceleration phenomenon, which is commonly defined to be the positive relationship between level of economic activity and changes in the inflation rate. ${ }^{21}$ Table 4 reports simulated cross correlations between the output gap and changes in inflation, i.e. $\operatorname{corr}\left(y_{t}, \pi_{t+2}-\pi_{t-2}\right)$. Corresponding historical values are:

\footnotetext{
${ }^{21}$ See Stock and Watson (1999), Fuhrer and Moore (1995), and Mankiw and Reis (2002) for further discussion.
} 
$\operatorname{corr}\left(y_{t}, \pi_{t+2}-\pi_{t-2}\right)=0.4491$ and $\operatorname{corr}\left(y_{t}, \pi_{t+4}-\pi_{t-4}\right)=0.5458$. As in the previous table, values are given for simulation samples of length $\mathrm{S}=5 \mathrm{~T}, 10 \mathrm{~T}, 20 \mathrm{~T}, 30 \mathrm{~T}, 50 \mathrm{~T}, 100 \mathrm{~T}$, where $\mathrm{T}$ is the historical data sample size. Of note is that results are independent of the level stickiness (compare Parts I and II of the table). Additionally, note that the sticky price model fails to reproduce the positive relation between inflation and the output gap. The sticky information model yields values that are closest to historical values for both measures. Thus, the sticky price model appears inadequate based upon these measures, sticky information model is preferred based on acceleration measure.

\subsection{Distributional Accuracy Tests $(\theta=0.5$ - Low Degree of Price Stickiness $)$}

The distributional accuracy tests tell a very different story in this case, than when $\theta=0.75$. In particular note in Panels II.A - II.C of Table 1 that the null hypothesis is never rejected. This suggests that when the degree of price stickiness is decreased, there is little to choose between the three models. Put differently, notice that the CS distributional accuracy measure for the sticky price with indexation model is still (often) lower than the comparable values for the other two models (see last three columns of the tables). However, the numerical values are so close together that, for a statistical perspective, there is nothing to choose between the models. This result is made more interesting by the fact that all models are clearly performing better in the case where $\theta=0.5$, as discussed above, and as is apparent upon noting that the CS distributional loss measures reported in the distributional accuracy tables are always lower when $\theta$ is reduced from 0.75 to 0.5.

\section{Concluding Remarks}

In this paper, we compared the theoretical and empirical performance of the sticky price model with two important alternatives, namely the sticky information model and the sticky price with indexation model. Based upon empirical observation of distributional fit (relative to the historical record) and based upon examination of various correlation features of simulated and historical inflation and output gap data, we find evidence that lower levels of price stickiness than suggested in some papers may be appropriate. Additionally, we find that impulse response functions of the alternative models are very close, with the important exception that there is no initial delay for inflation in the sticky price model. This is contrary to the structure of the other models, which yield delayed and gradual responses of inflation to monetary policy shocks. However, these responses 
have maximums after only 3 periods, so that the models are not significantly different from the sticky price model, as noted by the inability of our distributional accuracy tests to distinguish between the models when the level of price stickiness is low. Furthermore, the sticky price model is good at reproducing auto- and cross-correlations for low levels of price stickiness. Overall, we thus conclude that there is mild evidence in favor of the sticky information and sticky price with indexation models, although further investigation is needed in order to ascertain whether the newer sticky information and sticky price with indexation models will continue to dominate sticky price model upon both theoretical and empirical grounds. 


\section{References}

Backus, David K., P.J. Kehoe and F.E. Kydland, (1992), International Real Business Cycles, Journal of Political Economy, 101, 745-775.

Ball, L., (1994), Credible Disinflation with Staggered Price Setting, American Economic Review, 84, 282-289.

Ball, L., N.G. Mankiw, and R. Reis, (2003), Monetary Policy for Inattentive Economies, NBER Working Paper No. 9491.

Bernanke, B.S., and M. Gertler, (1995), Inside the Black Box: The Credit Channel of Monetary Policy Transmission, Journal of Economic Perspectives, vol. 9, 27-48.

Bierens, H.J., (2005), Econometric Analysis of Linearized Singular Dynamic Stochastic General Equilibrium Models, Journal of Econometrics, forthcoming.

Bierens, H.J., and N.R. Swanson, (2000), The Econometric Consequences of the Ceteris Paribus Condition in Theoretical Economics, Journal of Econometrics, 95, 223-253.

Bils, M., and P.J. Klenow, (2004), Some Evidence on the Importance of Sticky Prices, Journal of Political Economy 112, 947-985.

Blinder, A.,S., E.R. Canetti, D. Lebow, and J.B. Rudd, (1998), Asking About Prices: A New Approach to Understand Price Stickiness, New York: Russell Sage Foundation.

Calvo, G. A., (1983), Staggered Prices in a Utility Maximizing Framework, Journal of Monetary Economics, 12, 383-398.

Chang, Y.S., J.F. Gomes, and F. Schorfheide, (2002), Learning-by-Doing as a Propagation Mechanism, American Economic Review, 92, 1498-1520.

Christiano, L., M. Eichenbaum, and C.L. Evans, (2000), Monetary Policy Shocks: what have we Learned and to what End?, in J. Taylor and M. Woodford (eds.), Handbook of Macroeconomics, Amsterdam, The Netherlands: Elsevier.

Christiano, L.J., M. Eichenbaum, and C.L. Evans, (2001), Nominal Rigidities and the Dynamic Effects of a Shock to Monetary Policy, NBER Working Paper No. 8403.

Cogley, T., and J.M. Nason, (1993), Impulse Dynamics and Propagation Mechanism in a Real Business Cycle Models, Economics Letters, 43, 77-81.

Cogley, T., and J.M. Nason, (1995a), Output Dynamics for Real Business Cycles Models, American Economic Review, 85, 492-511.

Cogley, T., and J.M. Nason, (1995b), Effects of the Hodrick-Prescott filter on Trend and Difference Stationary Time Series: Implications for Business Cycle Research, Journal of Economic Dynamics and Control, 19, 253-278.

Cooley, Thomas F. and Gary D. Hansen, (1989), The Inflation Tax in a Real Business Cycle Model, American Economic Review, 79, 733-48.

Corradi, V. and N.R. Swanson, (2005a), A Test for Comparing Multiple Misspecified Conditional Interval Models, Econometric Theory, 21, 991-1016.

Corradi, V. and N.R. Swanson, (2005b), Evaluation of Dynamic Stochastic General Equilibrium Models Based on Distributional Comparison of Simulated and Historical Data, Journal of Econometrics, forthcoming. 
Corradi, V. and N.R. Swanson, (2006), Predictive Density Evaluation, in: Handbook of Economic Forecasting, eds. Clive W.J. Granger, Graham Elliot and Allan Timmerman, Elsevier, Amsterdam, pp. 197-284.

DeJong, M., B. Ingram, and C. Whiteman, (1996), A Bayesian Approach to Calibration, Journal of Business and Economic Statistics, 14, 1-9.

Del Negro, M. and F. Schorfheide, (2005), Monetary Policy Analysis with Potentially Misspecified Models, ECB Working Paper No. 475.

Diebold, F.X., and R.S. Mariano, (1995), Comparing Predictive Accuracy, Journal of Business and Economic Statistics, 13, 253-263.

Diebold, F.X., L.E. Ohanian, and J. Berkowitz, (1998), Dynamic Equilibrium Economies: A Framework for Comparing Models and Data, Review of Economic Studies, 65, 433-451.

Fernandez-Villaverde, J., and J.F. Rubio-Ramirez, (2004), Comparing Dynamic Equilibrium Models to Data: a Bayesian Approach, Journal of Econometrics, 123, 153 - 187.

Fuhrer, J., and G. Moore, (1995), Inflation Persistence, Quarterly Journal of Economics, CX, $127-160$

Gali., J. and M. Gertler, (1999), Inflation Dynamics: A Structural Econometric Analysis, Journal of Monetary Economics, 44, 195-222.

Gali, J., (2002), New Perspectives on Monetary Policy, Inflation, and the Business Cycle, NBER Working Paper No. 8767.

Gali, J., J.D. Lopez-Salido, and J. Valles, (2003), Technology shocks and monetary policy: assessing the Fed's performance, Journal of Monetary Economics, 50, 723-743.

Geweke, J., (1999a), Using Simulation Methods for Bayesian Econometric Models: Inference, Development, Communication Econometric Reviews, 18, 1-73.

Geweke, J., (1999b), Computational Experiments and Reality, Manuscript, University of Minnesota.

Gourieroux, C., A. Monfort and E. Renault., (1993), Indirect Inference, Journal of Applied Econometrics, 8, S85-S118.

Hodrick, R. and E. Prescott, (1997), Post-war US Business Cycles: An Empirical Investigation, Journal of Money, Credit and Banking, 29, 1-9.

Ireland, N.,P., (2004), Money's Role in the Monetary Business Cycle, Journal of Money Credit and Banking, 36, 969-984.

Khan, H. and Z. Zhu., (2002), Estimates of the Sticky-Information Phillips Curve for the United States, Canada, and the United Kingdom, Bank of Canada Working Paper No. 2002-19.

Korenok, O., (2004), Empirical Comparison of Sticky Price and Sticky Information Models, Manuscript, Rutgers University.

Korenok, O. and N.R. Swanson, (2005), The Incremental Predictive Information Associated with Using Theoretical New Keynesian DSGE Models Versus Simple Linear Alternatives, Oxford Bulletin of Economics and Statistics, 67, 905-930.

Korenok, O. and N.R. Swanson, (2006a), International Evidence on the Efficacy of New-Keynesian Models of Inflation Persistence, Working Paper, Rutgers University.

Korenok, O. and N.R. Swanson, (2006b), How Sticky Is Sticky Enough? A Distributional and Impulse Response Analysis of New Keynesian DSGE Models, Working Paper, Rutgers University. 
Kydland, F.E. and E.C. Prescott, (1982), Time to Build and Aggregate Fluctuations, Econometrica, 50, 1345-1370.

Lucas, Robert E., Jr., (1973), Some International Evidence on Output-Inflation Tradeoffs, American Economic Review, 63, 326-334.

Mankiw, N.,G., and R. Reis, (2002), Sticky Information Versus Sticky Prices: A Proposal to Replace the New Keynesian Phillips Curve, The Quarterly Journal of Economics, 117, 1295-1328.

Mankiw, N.,G., and L.H. Summers, (1986), Money Demand and the Effects of Fiscal Policies, Journal of Money, Credit, and Banking, 18, 415-429.

Phelps, E. S., (1970), Introduction: The New Microeconomics in Employment and Inflation Theory, in E.S. Phelps et al., Microeconomic Foundations of Employment and Inflation Theory, New York: Norton.

Rotemberg, J.J. and M. Woodford, (1996), Real Business Cycle Models and the Forecastable Movements in Output, Hours and Consumption, American Economic Review, 86, 71-89.

Sbordone, A., (2002), Prices and Unit Labor Costs: A New Test of Price Stickiness, Journal of Monetary Economics, 49, 265-292.

Schmitt-Grohe, S., (2000), Endogenous Business Cycles and the Dynamics of Output, Hours and Consumption, American Economic Review, 90, 1136-1159.

Sims, C. A., (2003), Implications of Rational Inattention, Journal of Monetary Economics, 50, 665-690.

Smets, F. and R. Wouters, (2003), An Estimated Dynamic Stochastic General Equilibrium Model of the Euro Area, Journal of the European Economic Association, 1, 1123-1175.

Smith, A.A., (1993), Estimating Nonlinear Time Series Models Using Simulated Vector Autoregressions, Journal of Applied Econometrics, 8, S63-S84.

Stock, J.H. and M.W. Watson, (1993), A Simple Estimator of Cointegrating Vectors in Higher Order Integrated Systems, Econometrica, 61, 783-820.

Stock, J.H. and M.W. Watson, (1999), Business Cycle Fluctuations in US Macroeconomic Time Series, in J. Taylor and M. Woodford (eds.), Handbook of Macroeconomics, Amsterdam, The Netherlands: Elsevier.

Swanson, N.R. and H. White, (1995), A Model Selection Approach to Assessing the Information in the Term Structure Using Linear Models and Artificial Neural Networks, Journal of Business and Economic Statistics, 13, 265-279.

Trabandt, M., (2005), Sticky Information vs. Sticky Prices: A Horse Race in a DSGE Framework, Manuscript, Humboldt University.

Watson, M.W., (1993), Measure of Fit for Calibrated Models, Journal of Political Economy, 101, 1011-1041.

Woodford, M., (2003a), Interest and Prices: Foundations of a Theory of Monetary Policy, Princeton University Press, Princeton, NJ.

Woodford, M., (2003b), Imperfect Common Knowledge and the Effects of Monetary Policy, Knowledge, Information, and Expectations in Modern Macroeconomics: In Honor of Edmund S. Phelps, Edited by P. Aghion, R. Frydman, J. Stiglitz, and M. Woodford, Princeton University Press, 25-59.

Yun, T., (1996), Nominal price rigidity, money supply endogeneity, and business cycles, Journal of Monetary Economics, 37, 345-370. 


\section{Table 1: Distributional Accuracy Tests Based on the Comparison of Historical and Simulated Inflation and the Output Gap Paths}

I. Information and Price Stickiness $\theta=0.75$

\begin{tabular}{|c|c|c|c|c|c|c|c|c|}
\hline \multicolumn{9}{|c|}{ A. Inflation $\left(\pi_{t}, \pi_{t-1}\right)$} \\
\hline \multirow[t]{2}{*}{$S, l$} & \multirow[t]{2}{*}{$Z$} & \multicolumn{2}{|c|}{ Crit. val. $\left(Z^{* *}\right)$} & \multicolumn{2}{|c|}{ Crit. val. $\left(Z^{*}\right)$} & \multicolumn{3}{|c|}{ CS Distributional Loss } \\
\hline & & $5 \%$ & $10 \%$ & $5 \%$ & $10 \%$ & $\mathrm{sp}$ & spi & si \\
\hline $10 \mathrm{~T}, 13$ & 0.0209 & 0.2163 & 0.1669 & 0.1700 & 0.1334 & 1.3056 & 1.2847 & 1.3187 \\
\hline $30 \mathrm{~T}, 13$ & 0.0400 & 0.1093 & 0.0874 & 0.0832 & 0.0607 & 1.3210 & 1.2810 & 1.3107 \\
\hline $50 \mathrm{~T}, 13$ & 0.0460 & 0.0830 & 0.0663 & 0.0586 & 0.0476 & 1.3233 & 1.2773 & 1.3149 \\
\hline \multicolumn{9}{|c|}{ B. Output Gap $\left(y_{t}^{g}, y_{t-1}^{g}\right)$} \\
\hline $10 \mathrm{~T}, 13$ & 0.1551 & 0.0363 & 0.0050 & 0.0014 & -0.0130 & 1.3509 & 1.1958 & 1.2940 \\
\hline $30 \mathrm{~T}, 13$ & 0.1044 & 0.0699 & 0.0497 & 0.0468 & 0.0370 & 1.2990 & 1.1946 & 1.3092 \\
\hline $50 \mathrm{~T}, 13$ & 0.0708 & 0.0586 & 0.0423 & 0.0425 & 0.0339 & 1.2802 & 1.2094 & 1.2926 \\
\hline \multicolumn{9}{|c|}{ C. Inflation and Output Gap $\left(\pi_{t}, y_{t}^{g}\right)$} \\
\hline $10 \mathrm{~T}, 13$ & 0.0995 & 0.1345 & 0.0820 & 0.0860 & 0.0550 & 1.3041 & 1.2046 & 1.2914 \\
\hline $30 \mathrm{~T}, 13$ & 0.0753 & 0.0761 & 0.0479 & 0.0481 & 0.0353 & 1.2775 & 1.2022 & 1.2805 \\
\hline $50 \mathrm{~T}, 13$ & 0.0578 & 0.0618 & 0.0458 & 0.0451 & 0.0295 & 1.2675 & 1.2097 & 1.2699 \\
\hline
\end{tabular}

II. Information and Price Stickiness $\theta=0.5$

A. Inflation $\left(\pi_{t}, \pi_{t-1}\right)$

\begin{tabular}{rrrrrrrrr}
\hline S,$l$ & $Z$ & Crit. val. $\left(Z^{* *}\right)$ & \multicolumn{2}{c}{ Crit. val. $\left(Z^{*}\right)$} & \multicolumn{3}{c}{ CS Distributional Loss } \\
& & $5 \%$ & $10 \%$ & $5 \%$ & $10 \%$ & sp & spi & si \\
\hline \hline $10 \mathrm{~T}, 13$ & -0.0008 & 0.1106 & 0.0885 & 0.0766 & 0.0559 & 1.2631 & 1.2639 & 1.2713 \\
$30 \mathrm{~T}, 13$ & -0.0016 & 0.0659 & 0.0369 & 0.0418 & 0.0300 & 1.2657 & 1.2673 & 1.2673 \\
$50 \mathrm{~T}, 13$ & 0.0006 & 0.0476 & 0.0268 & 0.0342 & 0.0194 & 1.2656 & 1.2650 & 1.2668 \\
\hline \multicolumn{8}{c}{ B. Output Gap $\left(y_{t}^{g}, y_{t-1}^{g}\right)$} \\
\hline $10 \mathrm{~T}, 13$ & 0.0026 & 0.0567 & 0.0445 & 0.0491 & 0.0375 & 1.1195 & 1.1169 & 1.1177 \\
$30 \mathrm{~T}, 13$ & 0.0005 & 0.0449 & 0.0362 & 0.0374 & 0.0327 & 1.1168 & 1.1162 & 1.1189 \\
$50 \mathrm{~T}, 13$ & -0.0014 & 0.0417 & 0.0356 & 0.0367 & 0.0329 & 1.1154 & 1.1168 & 1.1180 \\
\hline \multicolumn{8}{c}{ C. Inflation and Output Gap $\left(\pi_{t}, y_{t}^{g}\right)$} \\
\hline 10T,13 & 0.0124 & 0.0800 & 0.0537 & 0.0527 & 0.0346 & 1.1669 & 1.1545 & 1.1586 \\
$30 \mathrm{~T}, 13$ & 0.0119 & 0.0421 & 0.0321 & 0.0305 & 0.0217 & 1.1642 & 1.1523 & 1.1590 \\
$50 \mathrm{~T}, 13$ & 0.0083 & 0.0380 & 0.0252 & 0.0288 & 0.0209 & 1.1618 & 1.1535 & 1.1576 \\
\hline \hline
\end{tabular}

Notes: Joint distributions of inflation and/or the output gap are compared using the simulation based test statistic discussed above. The historical data period is 1964:1-2003:4. The second column of entries reports the numerical values of the test statistic, while the next four columns report $5 \%$ and $10 \%$ bootstrap critical values based on a bootstrap statistics for the cases where $T / S \rightarrow \delta>0\left(Z^{* *}\right)$ and $T / S \rightarrow 0\left(Z^{*}\right)$, where $T$ denotes the historical sample size and $S$ the length of the simulated sample. The last three columns of entries in the table report the Corradi and Swanson (2005b) distributional loss measure associated with model $i$, which is an estimate of $E\left(\left(F_{i}\left(u ; \theta_{i}^{\dagger}\right)-F_{0}\left(u ; \theta_{0}\right)\right)^{2}\right)$. Namely, we report $C S=\int_{U} \frac{1}{T} \sum_{t=1}^{T}\left(1\left\{Y_{t} \leq u\right\}-\frac{1}{S} \sum_{n=1}^{S} 1\left\{Y_{i, n}\left(\widehat{\theta}_{1, T}\right) \leq u\right\}\right)^{2} \phi(u) d u$ (see above for complete details). The CS distributional loss measure is calculated for the sticky price (sp), sticky price with indexation (spi) and sticky information (si) models. For the case where $S=T$ we set the block length used in the bootstrap as follows: $l 1=5, l 2=8, l 3=10, l 4=16$ and $l 5=20$. For all other cases, where $S=a T$, we set $l i$ equal to 'a' times the corresponding value of $l i$ when $S=T$. Selected results are reported in the table as results for other values of $S$ and $l$ are qualitatively the same - see working paper version of this paper (Korenok and Swanson (2006b)). All statistics are based on use of grids of 20x20 values for $u$ distributed uniformly across the historical data ranges of $\pi_{t}$ and $y_{t}^{g}$. Bootstrap empirical distributions are constructed using 500 bootstrap replications. Further details are given above. 


\section{Table 2: Directional Accuracy of Simulated Inflation and the Output Gap Paths}

I. Information and Price Stickiness $\theta=0.75$

\begin{tabular}{lrrrr}
\multicolumn{5}{c}{ A. Inflation } \\
\hline$\left(\pi_{t}, \pi_{t-1}\right)$ & data & sp & spi & si \\
\hline \hline (down, down) & 0.2025 & 0.2453 & 0.2518 & 0.2553 \\
(up, down) & 0.3038 & 0.2547 & 0.2512 & 0.2470 \\
(down, up) & 0.3038 & 0.2547 & 0.2482 & 0.2447 \\
(up, up) & 0.1899 & 0.2453 & 0.2488 & 0.2530 \\
p-value & 0.0068 & 0.0185 & 0.8868 & 0.0341 \\
\hline \multicolumn{5}{c}{ B. Output Gap } \\
\hline (down, down) & 0.3228 & 0.2653 & 0.2483 & 0.2508 \\
(up, down) & 0.2215 & 0.2341 & 0.2537 & 0.2464 \\
(down, up) & 0.2152 & 0.2340 & 0.2510 & 0.2485 \\
(up, up) & 0.2405 & 0.2666 & 0.2470 & 0.2543 \\
p-value & 0.1293 & 0.0000 & 0.2297 & 0.2006 \\
\hline \multicolumn{5}{c}{ C. Inflation and Output Gap } \\
\hline (down, down) & 0.2579 & 0.4589 & 0.3599 & 0.3848 \\
(up, down) & 0.2516 & 0.0411 & 0.1431 & 0.1174 \\
(down, up) & 0.2830 & 0.0404 & 0.1421 & 0.1123 \\
(up, up) & 0.2075 & 0.4596 & 0.3548 & 0.3854 \\
p-value & 0.3708 & 0.0000 & 0.0000 & 0.0000 \\
\hline \hline
\end{tabular}

II. Information and Price Stickiness $\theta=0.5$

\begin{tabular}{lrrrr}
\multicolumn{5}{c}{ A. Inflation } \\
\hline$\left(\pi_{t}, \pi_{t-1}\right)$ & data & sp & spi & si \\
\hline \hline (down, down) & 0.2025 & 0.2402 & 0.2477 & 0.2562 \\
(up, down) & 0.3038 & 0.2601 & 0.2513 & 0.2475 \\
(down, up) & 0.3038 & 0.2600 & 0.2525 & 0.2441 \\
(up, up) & 0.1899 & 0.2397 & 0.2484 & 0.2522 \\
p-value & 0.0068 & 0.0000 & 0.3270 & 0.0341 \\
\hline \multicolumn{5}{c}{ B. Output Gap } \\
\hline (down, down) & 0.3228 & 0.2509 & 0.2486 & 0.2483 \\
(up, down) & 0.2215 & 0.2475 & 0.2543 & 0.2470 \\
(down, up) & 0.2152 & 0.2474 & 0.2497 & 0.2500 \\
(up, up) & 0.2405 & 0.2542 & 0.2473 & 0.2547 \\
p-value & 0.1293 & 0.1952 & 0.3052 & 0.4598 \\
\hline \multicolumn{5}{c}{ C. Inflation and Output Gap } \\
\hline (down, down) & 0.2579 & 0.4642 & 0.3780 & 0.3523 \\
(up, down) & 0.2516 & 0.0361 & 0.1211 & 0.1514 \\
(down, up) & 0.2830 & 0.0341 & 0.1249 & 0.1430 \\
(up, up) & 0.2075 & 0.4656 & 0.3760 & 0.3533 \\
p-value & 0.3708 & 0.0000 & 0.0000 & 0.0000 \\
\hline \hline
\end{tabular}

Notes: Contingency tables are given for historical and simulated inflation $\left(\pi_{t}\right)$ and the output gap $\left(y_{t}^{g}\right)$ variables. Simulated data are based on the sticky price (sp), sticky price with indexation (spi) and sticky information (si) models. Historical data are for the period 1964:1-2003:4. The simulation sample size is 100T, where $\mathrm{T}$ is the historical data sample size. P-values reported in the last row of each panel in the table correspond to the $\chi^{2}$ test of independence. The statistic has a $\chi^{2}$ limiting distribution with 1 degree of freedom. 
Table 3: Autocorrelation and Cross Correlation: Inflation and the Output Gap I. Information and Price Stickiness $\theta=0.75$

\begin{tabular}{rrrrrrrrrr}
\hline $\mathrm{S}$ & \multicolumn{3}{c}{$\operatorname{corr}\left(\pi_{t}, \pi_{t-1}\right)$} & \multicolumn{3}{c}{$\operatorname{corr}\left(y_{t}^{g}, y_{t-1}^{g}\right)$} & \multicolumn{3}{c}{$\operatorname{corr}\left(y_{t}^{g}, \pi_{t}\right)$} \\
& $\mathrm{sp}$ & $\mathrm{spi}$ & $\mathrm{si}$ & $\mathrm{sp}$ & $\mathrm{spi}$ & si & sp & spi & si \\
\hline \hline $5 \mathrm{~T}$ & 0.8470 & 0.9027 & 0.9543 & 0.8841 & 0.7294 & 0.8579 & 0.9151 & 0.8379 & 0.9424 \\
$10 \mathrm{~T}$ & 0.8473 & 0.9146 & 0.9518 & 0.8826 & 0.7517 & 0.8611 & 0.9142 & 0.8411 & 0.9447 \\
$20 \mathrm{~T}$ & 0.8348 & 0.9199 & 0.9502 & 0.8721 & 0.7524 & 0.8598 & 0.9073 & 0.8432 & 0.9435 \\
$30 \mathrm{~T}$ & 0.8286 & 0.9172 & 0.9452 & 0.8662 & 0.7474 & 0.8451 & 0.9040 & 0.8417 & 0.9379 \\
$50 \mathrm{~T}$ & 0.8316 & 0.9158 & 0.9423 & 0.8691 & 0.7514 & 0.8387 & 0.9055 & 0.8419 & 0.9355 \\
$100 \mathrm{~T}$ & 0.8322 & 0.9176 & 0.9412 & 0.8695 & 0.7571 & 0.8366 & 0.9063 & 0.8437 & 0.9346 \\
\hline \hline
\end{tabular}

II. Information and Price Stickiness $\theta=0.5$

\begin{tabular}{rrrrrrrrrr}
\hline $\mathrm{S}$ & \multicolumn{3}{c}{$\operatorname{corr}\left(\pi_{t}, \pi_{t-1}\right)$} & \multicolumn{3}{c}{$\operatorname{corr}\left(y_{t}^{g}, y_{t-1}^{g}\right)$} & \multicolumn{3}{c}{$\operatorname{corr}\left(y_{t}^{g}, \pi_{t}\right)$} \\
& $\mathrm{sp}$ & $\mathrm{spi}$ & $\mathrm{si}$ & $\mathrm{sp}$ & $\mathrm{spi}$ & si & sp & spi & si \\
\hline \hline $5 \mathrm{~T}$ & 0.6584 & 0.7507 & 0.7475 & 0.7094 & 0.4958 & 0.5600 & 0.8075 & 0.8701 & 0.9442 \\
$10 \mathrm{~T}$ & 0.6468 & 0.7730 & 0.7602 & 0.6932 & 0.5065 & 0.5701 & 0.7972 & 0.8679 & 0.9437 \\
$20 \mathrm{~T}$ & 0.6467 & 0.7793 & 0.7585 & 0.6942 & 0.5095 & 0.5723 & 0.7974 & 0.8686 & 0.9459 \\
$30 \mathrm{~T}$ & 0.6403 & 0.7742 & 0.7435 & 0.6871 & 0.5075 & 0.5465 & 0.7945 & 0.8696 & 0.9425 \\
$50 \mathrm{~T}$ & 0.6415 & 0.7771 & 0.7397 & 0.6889 & 0.5088 & 0.5366 & 0.7945 & 0.8698 & 0.9405 \\
$100 \mathrm{~T}$ & 0.6457 & 0.7822 & 0.7368 & 0.6932 & 0.5141 & 0.5362 & 0.7977 & 0.8710 & 0.9412 \\
\hline \hline
\end{tabular}

Notes: Entries in the table correspond to autocorrelations of inflation $\left(\operatorname{corr}\left(\pi_{t}, \pi_{t-1}\right)\right)$ and the output gap $\left(\operatorname{corr}\left(y_{t}^{g}, y_{t-1}^{g}\right)\right)$, as well as the cross correlation between inflation and the output gap. Simulated data are based on the sticky price (sp), sticky price with indexation (spi) and sticky information (si) models. Historical data are for the period 1964:1-2003:4. Values are given for simulation samples of $\mathrm{S}=5 \mathrm{~T}, 10 \mathrm{~T}, 20 \mathrm{~T}, 30 \mathrm{~T}, 50 \mathrm{~T}, 100 \mathrm{~T}$, where $\mathrm{T}$ is the historical data sample size. Corresponding historical values are: $\operatorname{corr}\left(\pi_{t}, \pi_{t-1}\right)=0.8363, \operatorname{corr}\left(y_{t}^{g}, y_{t-1}^{g}\right)=0.8690, \operatorname{corr}\left(y_{t}^{g}, \pi_{t}\right)=0.2582$. 
Table 4: Correlation Between Output Gap and Change in Inflation: Acceleration Phenomena

I. Information and Price Stickiness $\theta=0.75$

\begin{tabular}{rrrrrrr}
\hline $\mathrm{S}$ & \multicolumn{2}{c}{$\operatorname{corr}\left(y_{t}^{g}, \pi_{t+2}-\pi_{t-2}\right)$} & \multicolumn{4}{c}{$\operatorname{corr}\left(y_{t}^{g}, \pi_{t+4}-\pi_{t-4}\right)$} \\
& $\mathrm{sp}$ & $\mathrm{spi}$ & $\mathrm{si}$ & $\mathrm{sp}$ & $\mathrm{spi}$ & $\mathrm{si}$ \\
\hline \hline $5 \mathrm{~T}$ & 0.1226 & 0.7854 & 0.4971 & 0.0765 & 0.7257 & 0.4466 \\
$10 \mathrm{~T}$ & 0.1213 & 0.7706 & 0.4984 & 0.0658 & 0.7132 & 0.4488 \\
$20 \mathrm{~T}$ & 0.1272 & 0.7600 & 0.5091 & 0.0743 & 0.7018 & 0.4599 \\
$30 \mathrm{~T}$ & 0.1323 & 0.7651 & 0.5292 & 0.0817 & 0.7068 & 0.4763 \\
$50 \mathrm{~T}$ & 0.1295 & 0.7693 & 0.5391 & 0.0776 & 0.7122 & 0.4851 \\
$100 \mathrm{~T}$ & 0.1302 & 0.7666 & 0.5450 & 0.0786 & 0.7103 & 0.4905 \\
\hline \hline
\end{tabular}

II. Information and Price Stickiness $\theta=0.5$

\begin{tabular}{rrrrrrr}
\hline $\mathrm{S}$ & \multicolumn{2}{c}{$\operatorname{corr}\left(y_{t}^{g}, \pi_{t+2}-\pi_{t-2}\right)$} & \multicolumn{4}{c}{$\operatorname{corr}\left(y_{t}^{g}, \pi_{t+4}-\pi_{t-4}\right)$} \\
& $\mathrm{sp}$ & $\mathrm{spi}$ & $\mathrm{si}$ & $\mathrm{sp}$ & $\mathrm{spi}$ & $\mathrm{si}$ \\
\hline \hline $5 \mathrm{~T}$ & 0.2044 & 0.7984 & 0.5966 & 0.1075 & 0.6552 & 0.4382 \\
$10 \mathrm{~T}$ & 0.2108 & 0.7844 & 0.5894 & 0.0975 & 0.6436 & 0.4317 \\
$20 \mathrm{~T}$ & 0.2085 & 0.7813 & 0.5964 & 0.1040 & 0.6431 & 0.4331 \\
$30 \mathrm{~T}$ & 0.2132 & 0.7852 & 0.6097 & 0.1138 & 0.6467 & 0.4368 \\
$50 \mathrm{~T}$ & 0.2118 & 0.7832 & 0.6110 & 0.1105 & 0.6417 & 0.4351 \\
$100 \mathrm{~T}$ & 0.2111 & 0.7803 & 0.6164 & 0.1107 & 0.6374 & 0.4419 \\
\hline \hline
\end{tabular}

Notes: See notes to Table 3. Corresponding historical values are $\operatorname{corr}\left(y_{t}^{g}, \pi_{t+2}-\pi_{t-2}\right)=0.4491$ and $\operatorname{corr}\left(y_{t}^{g}, \pi_{t+4}-\right.$ $\left.\pi_{t-4}\right)=0.5458$. 
Figure 1: Response to Anticipated Permanent Money Supply Shock
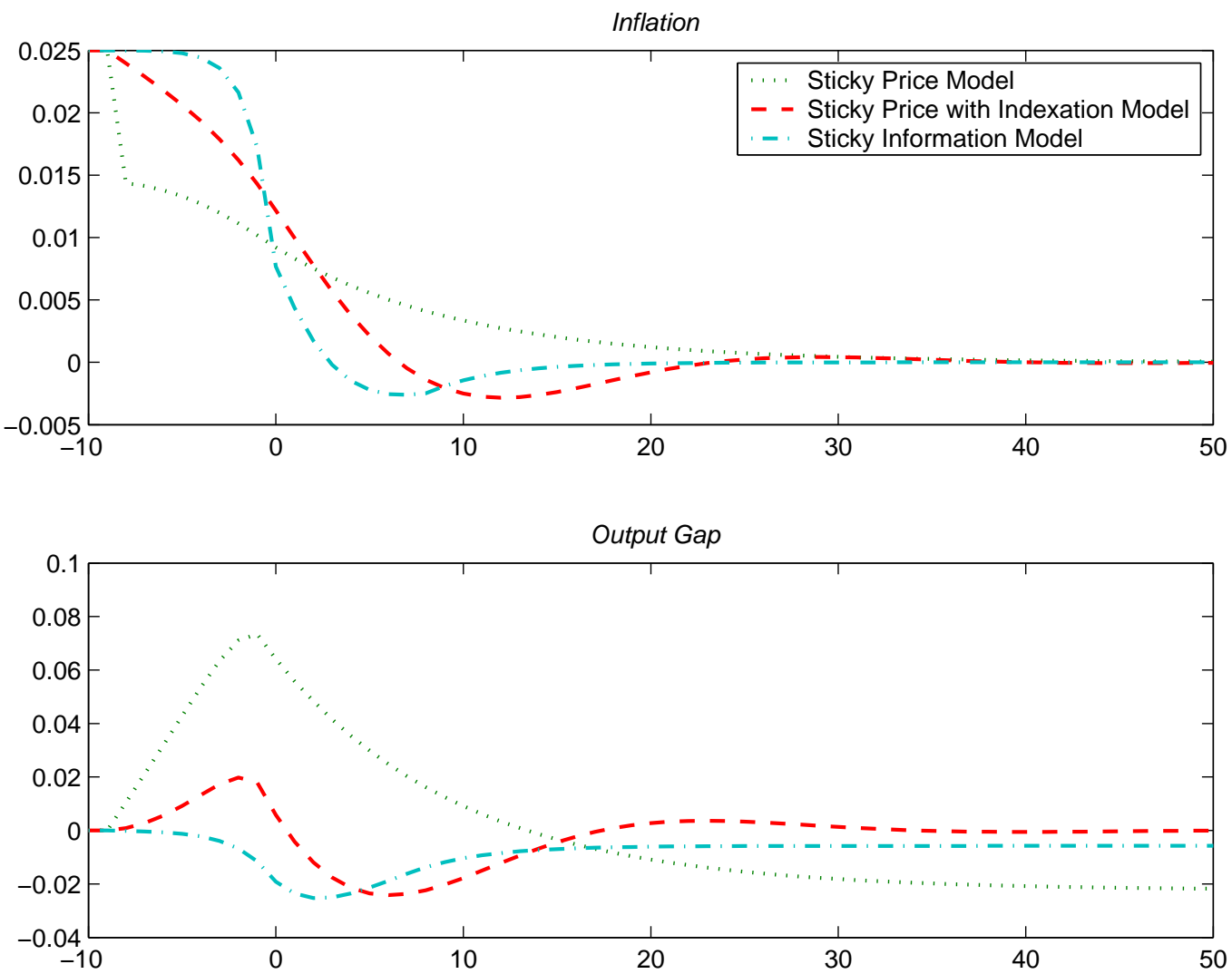

Notes: The size of the shock is equal to 0.025 . 


\section{Figure 2: Maximum Response of the Output Gap to Anticipated Money Supply}

Shock: Sticky Price Model

A. Change in $\eta$ and $\rho_{m}$

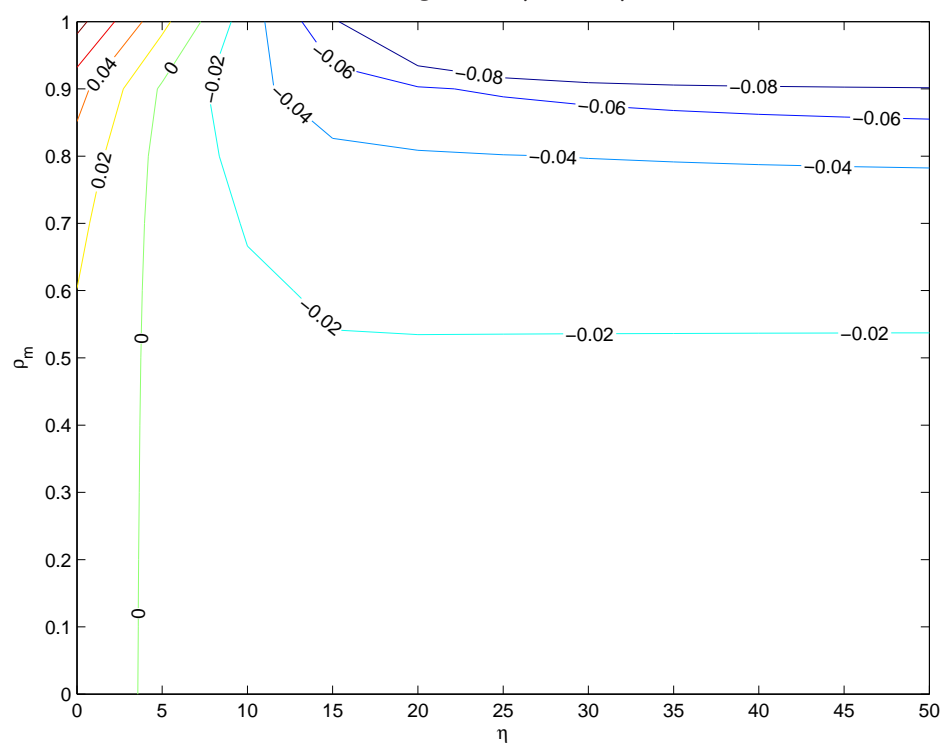

B. Change in $\eta$ and Anticipation Period

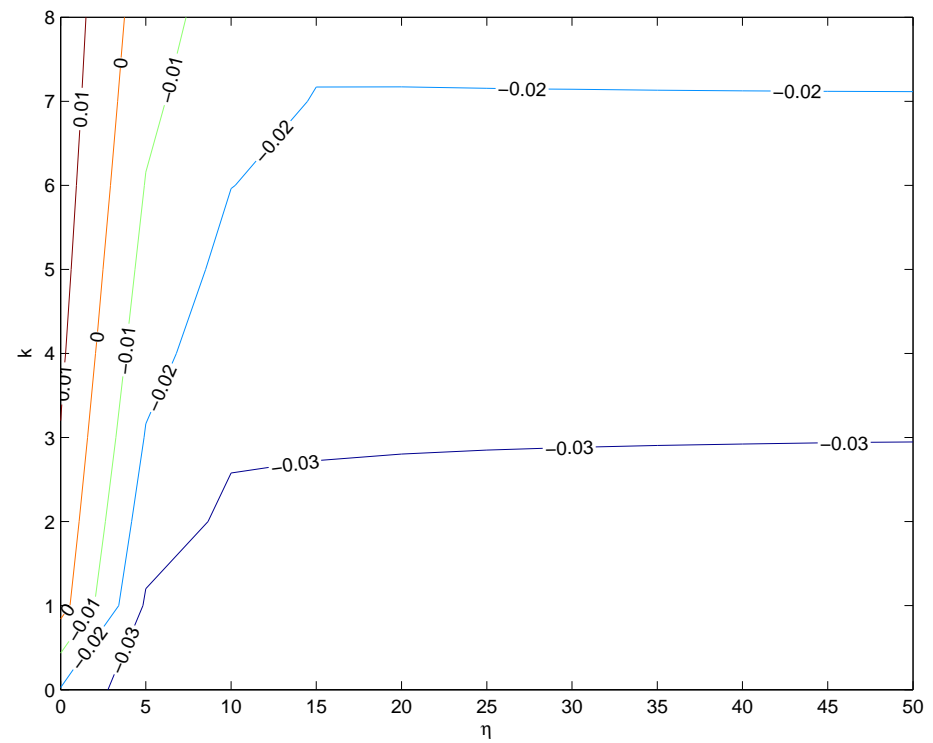

Notes: Graph A illustrates how the maximum of the output gap response to an anticipated money supply shock changes as interest rate semi-elasticity of money demand, $\eta$, and money shock persistence, $\rho_{m}$, change. Graph B illustrates how the maximum response of the output gap changes as $\eta$ and the anticipation period, $k$, change. All other parameter values are fixed at our baseline calibration. For example, the maximum of the response to an anticipated 8 quarter ahead $(k=8)$ permanent shock $\left(\rho_{m}=1\right)$, with other parameters fixed at baseline values $($ e.g. $\eta=1)$, is given in the upper left corner of Graph A. 
Figure 3: Impulse Response to Contractionary Money Supply Shocks
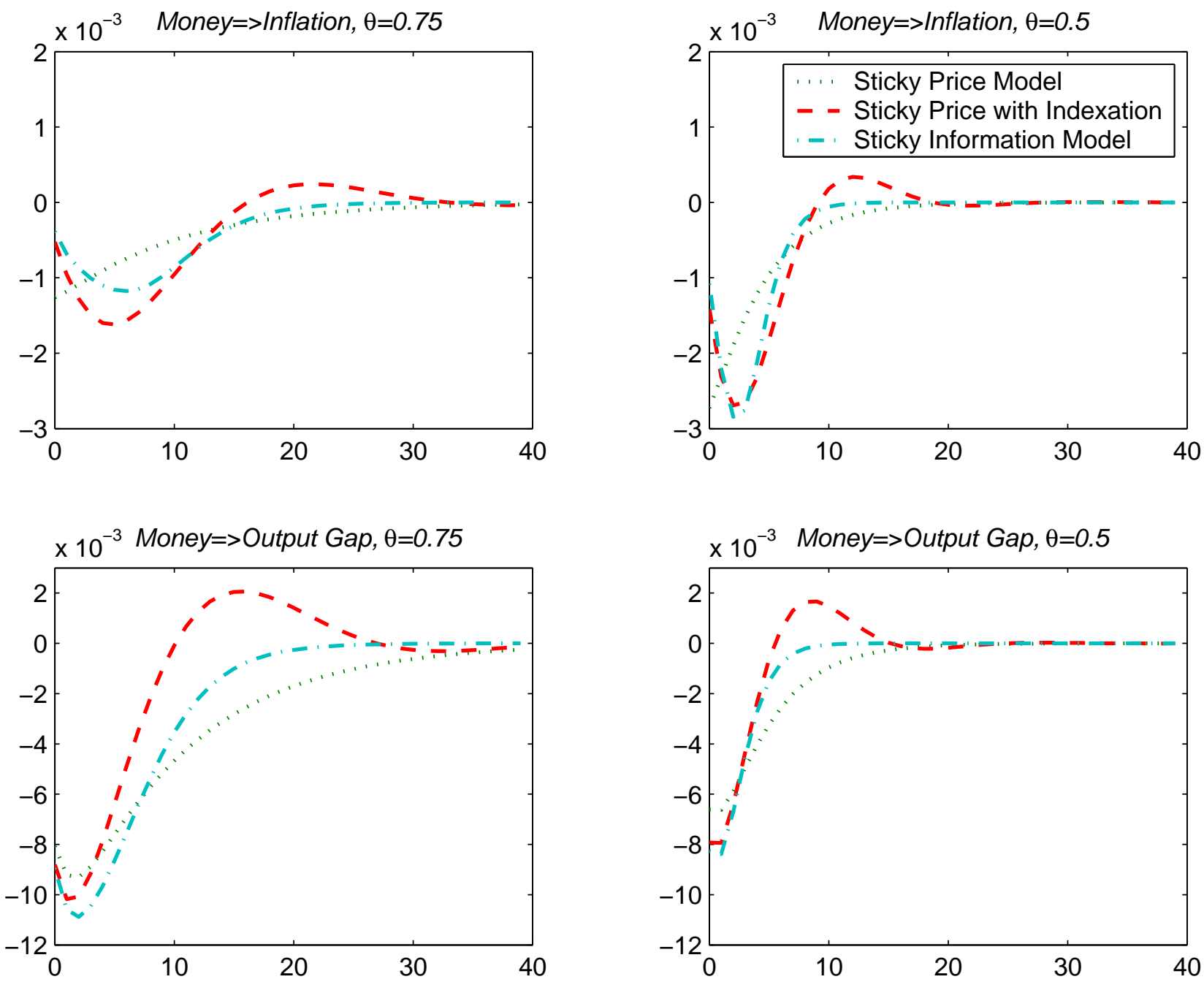

Notes: The size of the shock is equal to one standard deviation (i.e. $\sigma_{m}=0.007$ ). 
Figure 4: Impulse Response to Contractionary Technology Shocks
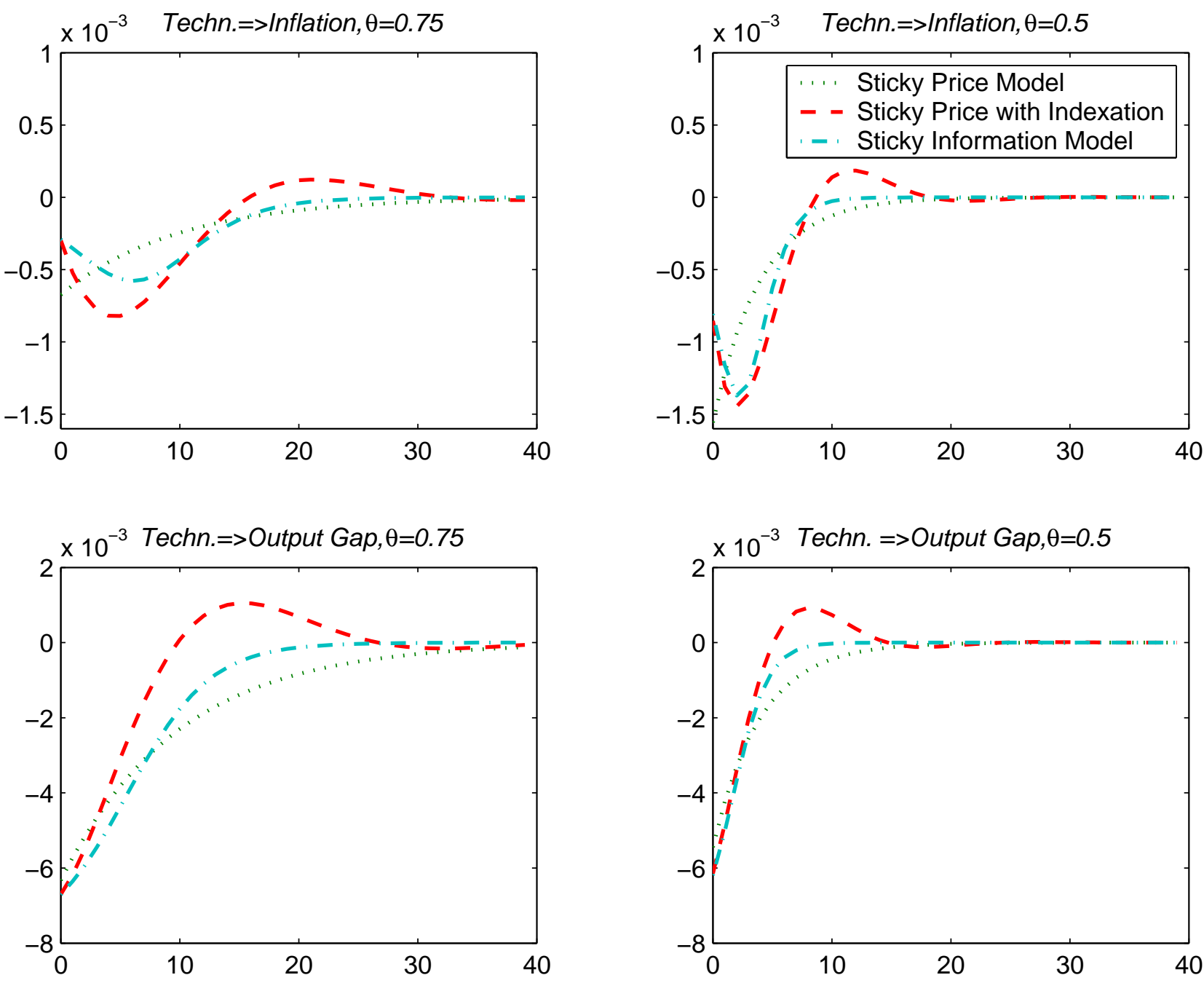

Notes: The size of the shock is equal to one standard deviation (i.e. $\sigma_{a}=0.007$ ). 
Figure 5: Historical and Simulated Empirical Densities of Inflation and the Output Gap

Inflation, $\theta=0.75$

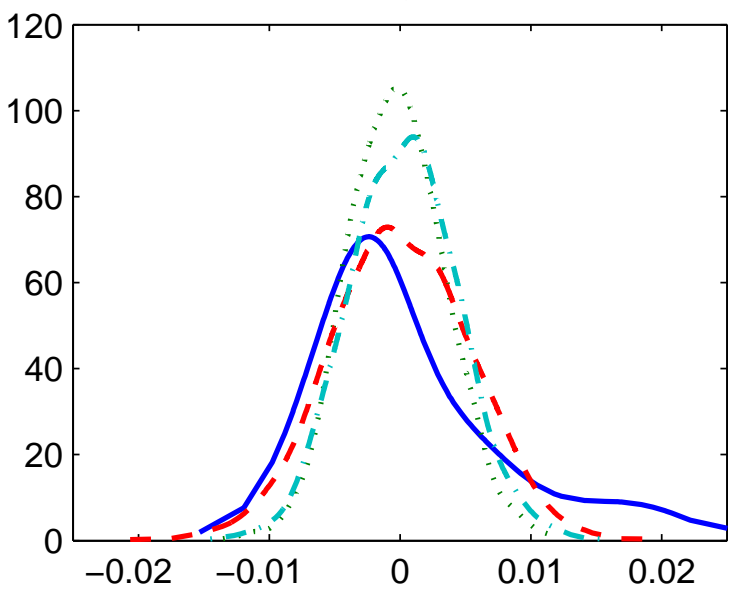

Output Gap, $\theta=0.75$

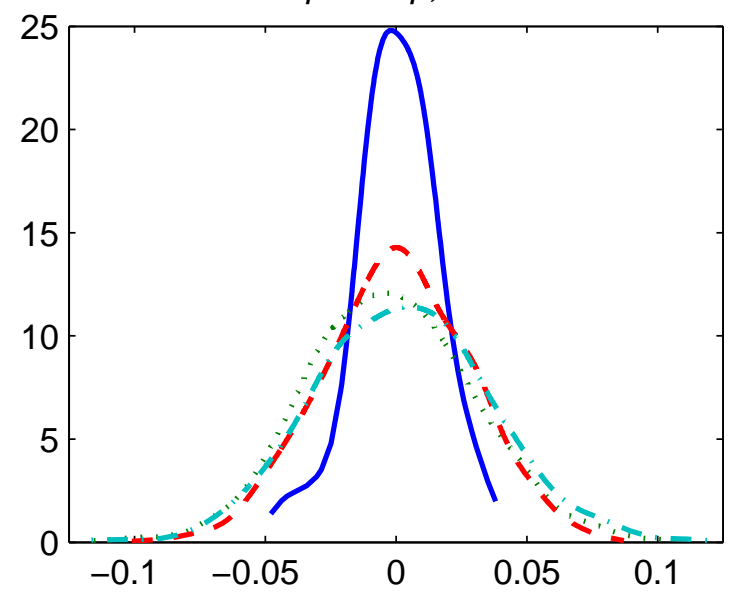

Inflation, $\theta=0.5$

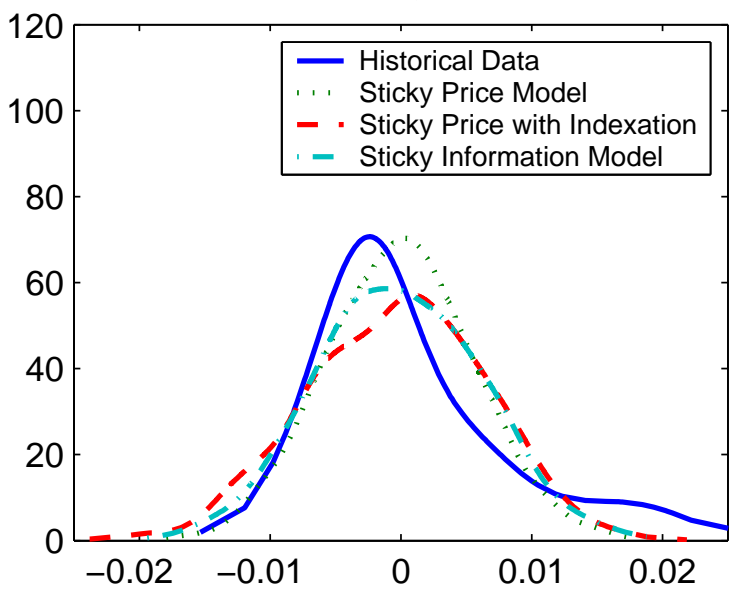

Output Gap, $\theta=0.5$

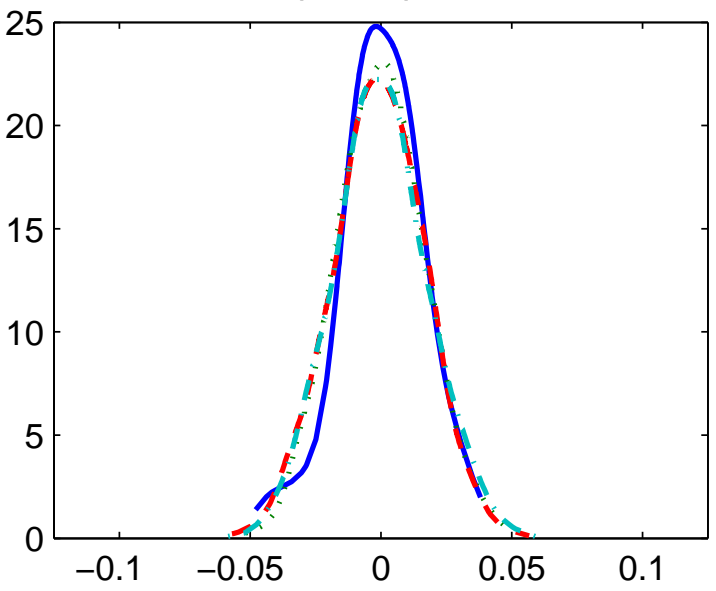

Notes: Plots of densities correspond to simulated distributions used in the statistical comparison of the sticky price, sticky price with indexation, and sticky information models are given for $\pi_{t}$ and $y_{t}^{g}$. Simulated data are based on the sticky price (sp), sticky price with indexation (spi) and sticky information (si) models. Historical data are for the period 1964:1-2003:4. The simulation sample size is 100T, where $\mathrm{T}$ is the historical data sample size. 